\title{
Letter \\ Understanding Lateral Marsh Edge Erosion with Terrestrial Laser Scanning (TLS)
}

\author{
Thomas P. Huff *, Rusty A. Feagin and Arturo Delgado Jr.
}

Department of Ecosystem Science and Management, Texas A\&M University, College Station, TX 77845, USA; feaginr@tamu.edu (R.A.F.); delgado1984@tamu.edu (A.D.)

* Correspondence: thomas2013@tamu.edu

Received: 19 August 2019; Accepted: 19 September 2019; Published: 21 September 2019

\begin{abstract}
Coastal wetlands are a crucial buffer zone between land and sea but lateral erosion threatens their long-term sustainability. Better understanding of the forces leading to lateral marsh retreat will benefit the assessment of management options applied to mitigate the erosion. Terrestrial Laser Scanning (TLS), Light Detection and Ranging (lidar), and associated technologies are increasingly being used to assess this erosion. The central objective of this study was to identify a methodology for measuring marsh edge erosion with a TLS and correlate that erosion with exposed roots and incident wave energy. We quantified edge erosion across multiple temporal and spatial scales using a TLS, showing greater than one meter of lateral erosion over a 318-day period. We then evaluated the relationships between the erosion and incident wave energy along with erosion and vegetation roots. Wave height and erosion was strongly related $\left(r^{2}=0.99\right)$, while vegetation roots did not show an apparent effect. We discuss the challenges that arise from using TLS equipment, TLS data sets, and the use of voxels to measure marsh edge erosion.
\end{abstract}

Keywords: lidar; terrestrial laser scanner; voxelization; marsh edge erosion; wind waves

\section{Introduction}

Coastal zones are in a constant state of physical and geological flux caused by tidal activity, sea level rise, and high energy events such as strong storms. Wave erosion threatens wetland ecosystems and can have negative impacts on the provision of ecosystem services to people and the surrounding environment [1]. Wind waves in estuaries and shallow bays can be influenced by wind speed, wind direction, fetch distance, and water depth [2]. Wave height and water level are strong contributors to the lateral erosion of salt marsh edges [3-6]. Still, questions remain about the best way to predict and measure the influence of contributing factors, such as vegetation or gravity-induced slumping, to overall marsh edge retreat [7-11].

Some previous studies have quantified marsh edge retreat using Unmanned Aerial Systems (UAS) $[12,13]$. Images are quickly gathered and are of a much higher spatial resolution than traditional aerial photography, resulting in the ability to study marsh edge retreat caused by individual storm events. However, the images gathered by both methods are usually nadir-oriented, only allowing for a two-dimensional assessment of marsh retreat with little information about the vertical edge. Methods such as structure from motion (SfM) can give a three-dimensional product useful for surface topographic modeling. However, this method is not applicable to most salt marsh edge erosion studies due to soil and plants overhanging the scarped marsh edge. This overhang creates a shadow in the imagery. To minimize the shadowing an angle close to 90 degrees from the scarped edge is desirable for data acquisition.

Terrestrial Laser Scanning (TLS) with Light Detection and Ranging (lidar) has been used to three-dimensionally measure coastal cliff geometry, salt marsh morphology, beach and sediment volume 
changes, and dune erosion and wave overtopping [14-19]. Nguyen et al. (2016-2018) used voxelization at varying scales along with $\mathrm{k}$-means to classify voxels [20,21]. This showed the potential for terrestrial lidar to be classified in similar methods to traditional aerial imagery. However, Nguyen et al. (2016-2018) were still studying the surface of the marsh and not the retreating edge $[20,21]$. TLS was used to measure retreating cliff edges by Olson et al. who showed a 30 percent measurement improvement of terrestrial lidar over aerial lidar when measuring cliff edge erosion [14]. To our knowledge, use of lidar to quantify salt marsh edge erosion and tie it to the responsible physical factors is relatively limited.

The central objective of this study was to establish a method that was capable of measuring marsh edge erosion accurately and correlating erosion with root presence and wave energy. To accomplish this, the first objective was to quantify tidal marsh edge erosion across temporal and spatial scales using a TLS. The second objective was to evaluate the relationships between marsh edge erosion and two factors, root presence and incident wave energy. To measure each factor and test for correlations, several novel methods were used.

\section{Methods}

\subsection{Terrestrial Laser Scanning of Erosion}

The study area was located on an eroding edge of a salt marsh wetland known as Anchor Bay (Figure 1), located at the terrestrial-aquatic interface of Galveston Island, Texas, and West Galveston Bay (also known as West Bay). Galveston Island is a barrier island on the Texas Gulf Coast, located about 50 miles southeast of Houston, Texas, U.S.A. The island stretches $43.5 \mathrm{~km}$ long by $5 \mathrm{~km}$ wide at its widest point. The island is oriented northeast-southwest, with the Gulf of Mexico bordering on the east and south, West Bay on the west, and Galveston Bay towards the north.

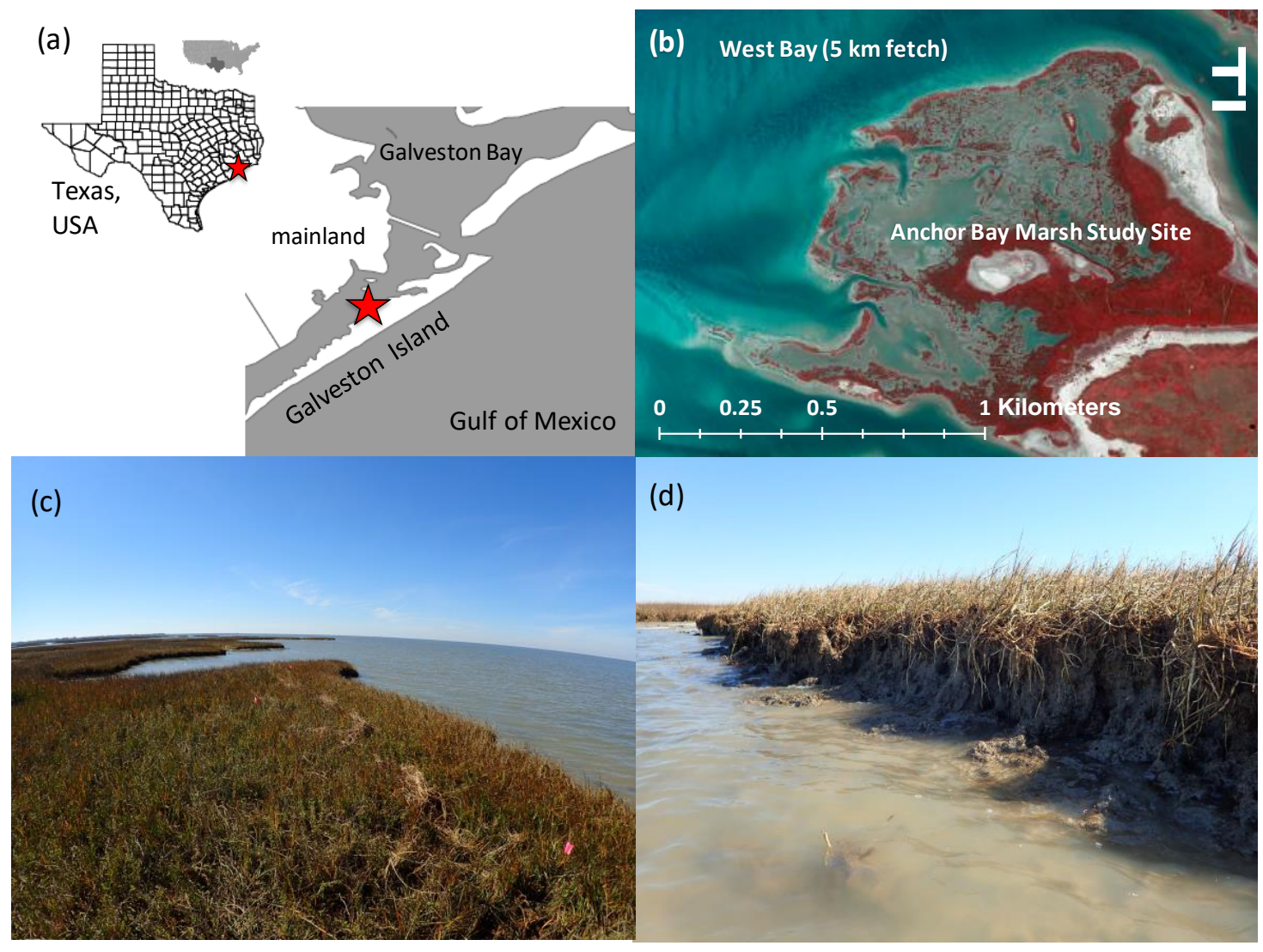

Figure 1. (a) Location of the marsh area study site in relation to its location on Galveston Island, Texas. (b) False color composite aerial imagery of the marsh study site in Anchor Bay. (c) and (d) Photos of the marsh study site taken on 26 February, 2015. 
TLS scans were conducted to create a 3D model of the marsh edge at multiple dates (26 February, 2015; 6 March, 2015; 30 April, 2015; 24 August, 2015; and 10 January, 2016). These scans included both a high resolution photographic picture and distance measurements recorded using lidar technology.

For each scan, a Leica ScanStation 2 equipped with a 3R (IEC-60825-1) visible green laser with a maximum average radiant power of $1.5 \mathrm{~mW}$ (wavelength 400-700 nm) was used on a tripod stationed on a survey benchmark set approximately $8 \mathrm{~m}$ from the marsh edge in the water (Figure 2 ). A $2 \mathrm{~cm}$ point spacing was selected as a compromise between scanning speed and resolution. Before the study began, we developed a novel and semi-permanent benchmark that followed the standard USGS methods for unconsolidated marshes, but was modified for placement in the submerged water off the marsh edge [22]. A survey tripod with a central pole was used to ensure the tripod was stationed directly above the survey marker. This central pole was shorter than normal which allowed the 3 tripod legs to be placed deep into the soft substrate while the central pole still contacted the underwater survey marker.

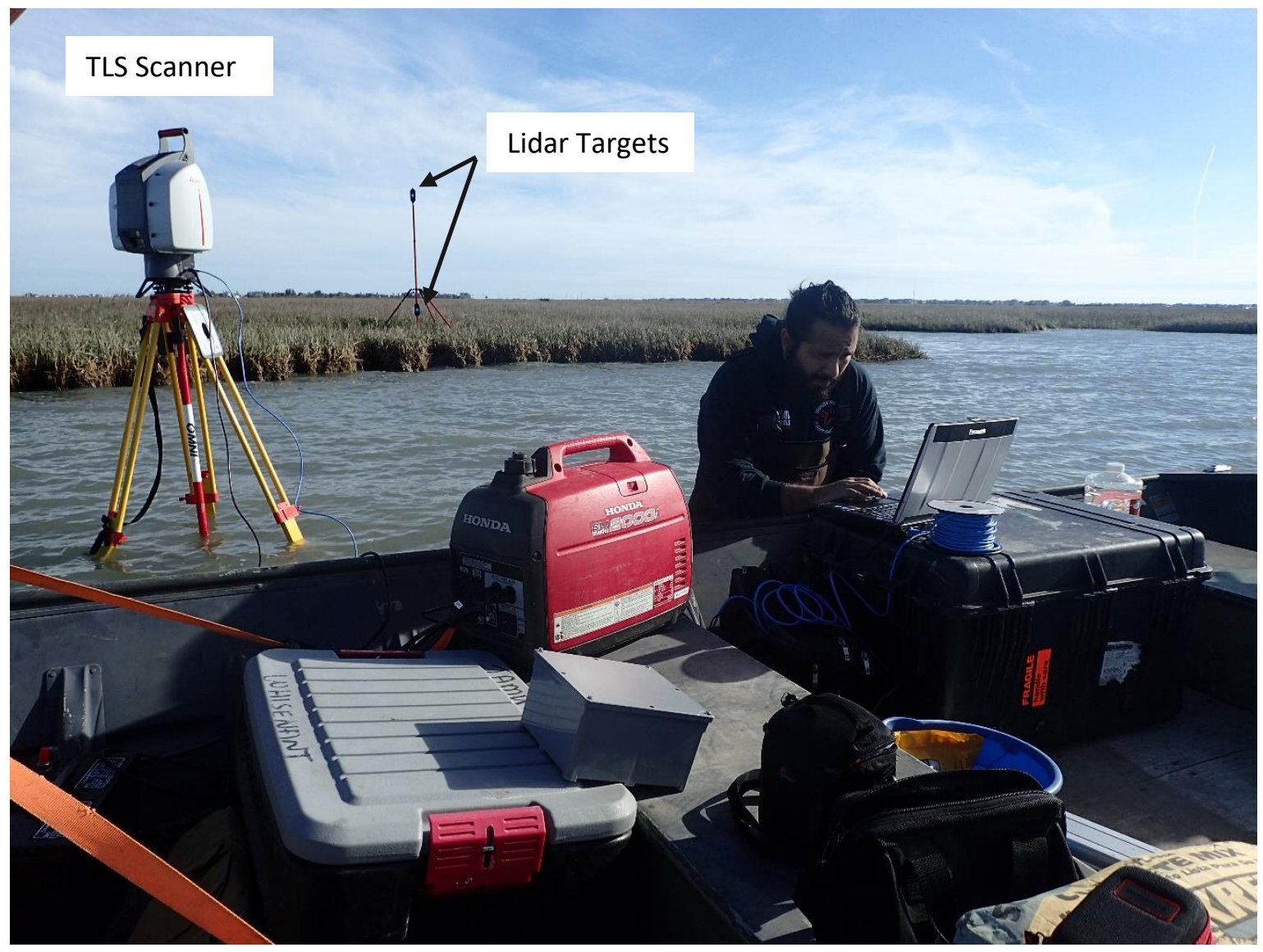

Figure 2. Photo of the Terrestrial Laser Scanning (TLS) scan assembly. The scanner tripod is placed over a concrete survey marker with reflective Light Detection and Ranging (lidar) targets on concrete benchmarks atop the marsh surface.

To minimize geo-referencing errors, benchmarks were constructed following standard USGS methods for unconsolidated marshes, and reflective targets were placed on top of them [22]. Additional survey stakes and PVC pipes were placed on the left and right outer edge of the site boundary. A $0.02 \mathrm{~m}$ horizontal and $0.02 \mathrm{~m}$ vertical point spacing (set at $8 \mathrm{~m}$ of distance) was used to scan the marsh edge. Co-located, high-resolution photographic images were also collected during each scan.

Point cloud post-processing was conducted in CloudCompare 2.6.1 [23]. Each point cloud was co-registered using a manual point pair-picking method, and a transformation matrix was then applied. 
Any points that were associated with the above ground portions of vegetation (stems, leaves, flowering portions) were removed along with any erroneous returns.

The point cloud from the first collection date was then compared with all subsequent dates using the Cloud-to-Cloud (C2C) algorithm [24]. We called these comparisons interval 1 (i.e., difference between 26 February, 2015 and 6 March, 2015), interval 2, interval 3, and interval 4. With C2C, the change between two datasets was estimated by calculating the distances between the two point clouds, while also avoiding the problems commonly associated with raster analysis such as gridding or meshing of point clouds. The Multiscale Model to Model Cloud Comparison (M3C2) algorithm was also used [24,25]. With M3C2, the distances between the point clouds were calculated using local point cloud normals, requiring user-defined normal scale $(0.02 \mathrm{~m})$ projection scale $(2.5 \mathrm{~m})$, and maximum cylinder depth $(2.5 \mathrm{~m})$. Point cloud normals were fixed in the horizontal direction and core point subsets were not utilized. For $\mathrm{M} 3 \mathrm{C} 2$, registration errors for the comparative datasets were defined as: Interval $1(0.05 \mathrm{~m})$, interval $2(0.12 \mathrm{~m})$, interval $3(0.11 \mathrm{~m})$, and interval $4(0.04 \mathrm{~m})$.

\subsection{Voxel Analysis: Correlating Roots with Erosion}

We sought to relate the erosion measured by the TLS distance measurements with the number of roots visible in the co-located, high-resolution photographic images. First, roots and other features were manually identified by picking visually identified points in the images using ENVI 5.1, and regions of interest (ROI) were established such that individual points were identified as belonging to one of four possible classes: (1) Roots, (2) soil, (3) flare roots, and (4) flare soil. "Flare roots" and "flare soil" were those respective features that appeared abnormally bright due to the glare of the sun in some portions of the imagery. The red band, green band, and blue band values for the points were documented. In general, flare locations were abnormally high in the RGB values. Reference pixels were selected from each class and a histogram comparison of the imagery bands were conducted to find the proper color ranges using R 2.1. The histograms from each band then were fed through a simple decision tree classification script built in R 2.1 to sort points into the four possible classes. The result of this comparison showed that the band values for all colors needed to fall between 55 and 80 based on an 8-bit band resolution to be classified as roots. The decision tree script used a simple "if else" decision structure. For example, for a voxel to be classified as "roots", the red band values fell between 55 and 80, the green band values fell between 55 and 80, and the blue band fell between 55 and 80. If all of these filters were met then the voxel was determined to be a root. This method was repeated for each class using unique ranges. The most conservative value range was 55 to 80 and reduced the possibility of false positives with regards to classifying roots. This approach minimized the commission errors within the soil class to $2.49 \%$ and the two flare classes to $0 \%$ (Table 1 ).

Table 1. Accuracy assessment for the root classification effort listing the percentage of time that a commission error occurred for a given class by band.

\begin{tabular}{|c|c|c|c|c|}
\hline \multicolumn{5}{|c|}{ Was a Commission Error Made and What Percent of the Time did It Happen? } \\
\hline & $\begin{array}{l}\text { 55-80 Red Values } \\
\text { Band } 1\end{array}$ & $\begin{array}{l}55-80 \text { Green } \\
\text { Values Band } 2\end{array}$ & $\begin{array}{l}\text { 55-80 Blue Values } \\
\text { Band } 3\end{array}$ & $\begin{array}{c}\text { 55-80 RGB Values } \\
\text { All Bands }\end{array}$ \\
\hline & $\%$ Yes & $\%$ Yes & $\%$ Yes & $\%$ Yes \\
\hline Roots & $37.25 \%$ & $38.10 \%$ & $16.68 \%$ & $14.50 \%$ \\
\hline Soil & $5.94 \%$ & $5.94 \%$ & $2.49 \%$ & $2.49 \%$ \\
\hline Flare Soil & $14.78 \%$ & $27.83 \%$ & $49.57 \%$ & $0.00 \%$ \\
\hline Flare Roots & $0.00 \%$ & $0.00 \%$ & $0.23 \%$ & $0.00 \%$ \\
\hline
\end{tabular}

We then sought to identify whether the lateral erosion within subsampled portions of the TLS scene (using the lidar distance measurements) were correlated with the proportion of root points within those same subsampled portions (using the classification effort based on the photographic 
images). To accomplish this, a custom script in R Studio 2.1 was written to identify the number of root-classified points and the average amount of erosion within corresponding voxels (i.e., volumetric pixels) across the entire TLS scene [26]. This analysis was conducted using four sets of voxel sizes, over each of the time intervals: $5 \mathrm{~cm} \times 5 \mathrm{~cm}, 10 \mathrm{~cm} \times 10 \mathrm{~cm}, 50 \mathrm{~cm} \times 50 \mathrm{~cm}$, and $100 \mathrm{~cm} \times 100 \mathrm{~cm}$. Statistical regression was then conducted for each scale and time interval separately, where the average erosion was assumed dependent to the number of root points per voxel. Results were assessed with r-squares and p-values.

\subsection{Correlating Incident Waves with Erosion}

We also sought to determine if the lateral erosion was related to the wave energy that intercepted the marsh edge. To measure waves, an ultrasonic wave sensor (T30UXUB, Banner Engineering, Inc.) was placed approximately $5 \mathrm{~m}$ offshore from the marsh edge for a duration of nine days (10 December to 18 December, 2015), with a sample rate of $20 \mathrm{~Hz}$. A custom script in R 2.1 was used to convert the collected sensor data from voltage to water level in $\mathrm{cm}$, based on a distance calibration set up before the sensor was placed into the field [26]. During the time period in the field, a large range of sea state conditions were encountered, with wind occurring from every cardinal and primary intercardinal direction and speeds ranging from $5.6 \mathrm{kph}$ to $39 \mathrm{kph}$, arising across a maximum fetch of approximately $6.25 \mathrm{~km}$.

A 1-minute subset was extracted from each 2-hour interval of data for subsequent analysis. A total of 118 1-minute subsets, each containing 1200 data points, were extracted and compiled. MATLAB toolboxes were then utilized on each subset to smooth noise and data spikes, and calculate the free surface elevation power spectral density, significant wave height ( $\mathrm{Hm} 0)$, wave frequency $(\mathrm{Tp})$, and wave period (fp) $[27,28]$.

To identify a possible relationship between these 1-minute wave statistics and wind forces during those times, hourly wind speed and wind direction data were acquired from the Scholes International airport weather station in Galveston ( $7.3 \mathrm{~km}$ distance from the wave sensor location). Wind directional groups (WDGs) were created and grouped for analysis as follows: Wind direction group 1 (WDG 1) includes ENE, NE, NNE, and N; wind direction group 2 (WDG 2) includes NNW, NW, WNW, and W; and wind direction group 3 (WDG 3) includes WSW, SW, SSW, S, SSE, SE, ESE, and E. For each WDG, recorded wave heights were regressed linearly with recorded wind speed with r-squared used for goodness of fit and p-value used for significance (Figure 3). The resulting regression equations constituted a model that could be used for hindcasting back in time, or forecasting forward in time.

The WDG model equations were identified as follows:

$$
\begin{gathered}
y=1.0056 x-4.1377(\text { WDG } 1) \\
y=0.5699 x+7.4852(\text { WDG } 2) \\
y=-0.0133 x+4.3199(\text { WDG3 })
\end{gathered}
$$

Wind data was then fed into the equation with the corresponding wind direction for all available times within the 318-day period of the wave record. The predicted wave heights were then summed cumulatively over the period. 

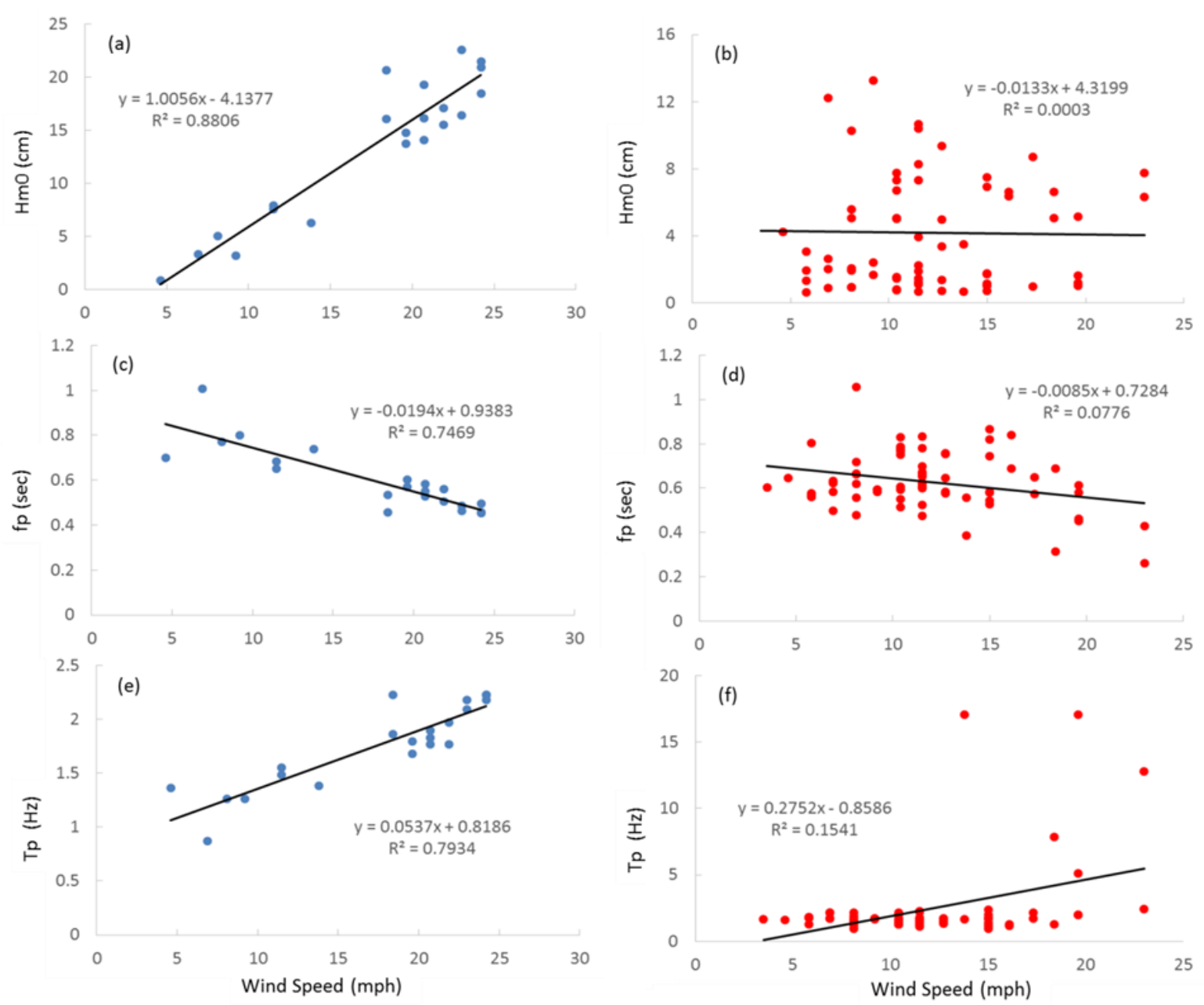

Figure 3. Wind directional group (WDG) 1 (left column in blue) and WDG 3 (right column in red) regression analysis for wind speed (independent) versus dependent variables (a) and (b) significant wave height $(\mathrm{Hm} 0) ;(\mathbf{c})$ and $(\mathbf{d})$ wave period $(\mathrm{fp})$; and (e) and (f) wave frequency $(\mathrm{Tp})$. Note that the $y$ axis units are different on each graph.

\section{Results}

Lateral erosion of the marsh edge increased substantially over time (Table 2), and the increasing trend was similarly recorded by the $\mathrm{C} 2 \mathrm{C}$ and $\mathrm{M} 3 \mathrm{C} 2$ metrics. Erosion was generally related to the duration of each interval, with less erosion over shorter time periods with each time interval overlapping (interval 1 was 6 days long, interval 2 was 63 days long, interval 3 was 179 days long, and interval 4 was 318 days long). The time frames were selected and compared to measure the cumulative linear relationship between erosion and waves, as this was of interest to other related research where we are building an equation to estimate erosion over different time scales. C2C and M3C2 erosion estimates were correlated with an $\mathrm{r}^{2}=0.93$, with $\mathrm{C} 2 \mathrm{C}$ under estimating $\mathrm{M} 3 \mathrm{C} 2$ by $-0.2313 \mathrm{~m}$ on average. M3C2 produced a greater erosion value of $1.301 \mathrm{~m}$ of erosion in the landward direction in the 318-day period.

The spatial patterning of erosion was similarly recorded by the $\mathrm{C} 2 \mathrm{C}$ metric (Figure $4 \mathrm{a}-\mathrm{d}$ ) as compared with the M3C2 (Figure 5a-d) metric. The patterning of the erosion visually appeared to match up with the undulating topography of the edge, such that protruding portions eroded more quickly than small embayments, as best expressed in Figure 4c. In general, the erosion recorded by the two metrics was greatest on the left (east) side of the scanned marsh edge. 
Table 2. Average erosion loss results from the Multi-Model to Model Cloud Comparison (M3C2) and Cloud-to-Cloud (C2C) algorithms for each interval.

\begin{tabular}{lccccc}
\hline & $\begin{array}{c}\text { M3C2 } \\
\text { Distance (m) }\end{array}$ & $\begin{array}{c}\text { C2C Absolute } \\
\text { Distance (m) }\end{array}$ & $\begin{array}{c}\text { C2C Absolute } \\
\text { Distance X (m) }\end{array}$ & $\begin{array}{c}\text { C2C Absolute } \\
\text { Distance Y (m) }\end{array}$ & $\begin{array}{c}\text { C2C Absolute } \\
\text { Distance Z (m) }\end{array}$ \\
\hline Interval 1 & -0.081 & -0.025 & 0.004 & 0.004 & -0.002 \\
\hline Interval 2 & -0.432 & -0.184 & -0.082 & -0.108 & -0.032 \\
\hline Interval 3 & -0.903 & -0.488 & -0.251 & -0.323 & -0.064 \\
\hline Interval 4 & -1.301 & -1.095 & -0.582 & -0.790 & -0.160 \\
\hline
\end{tabular}

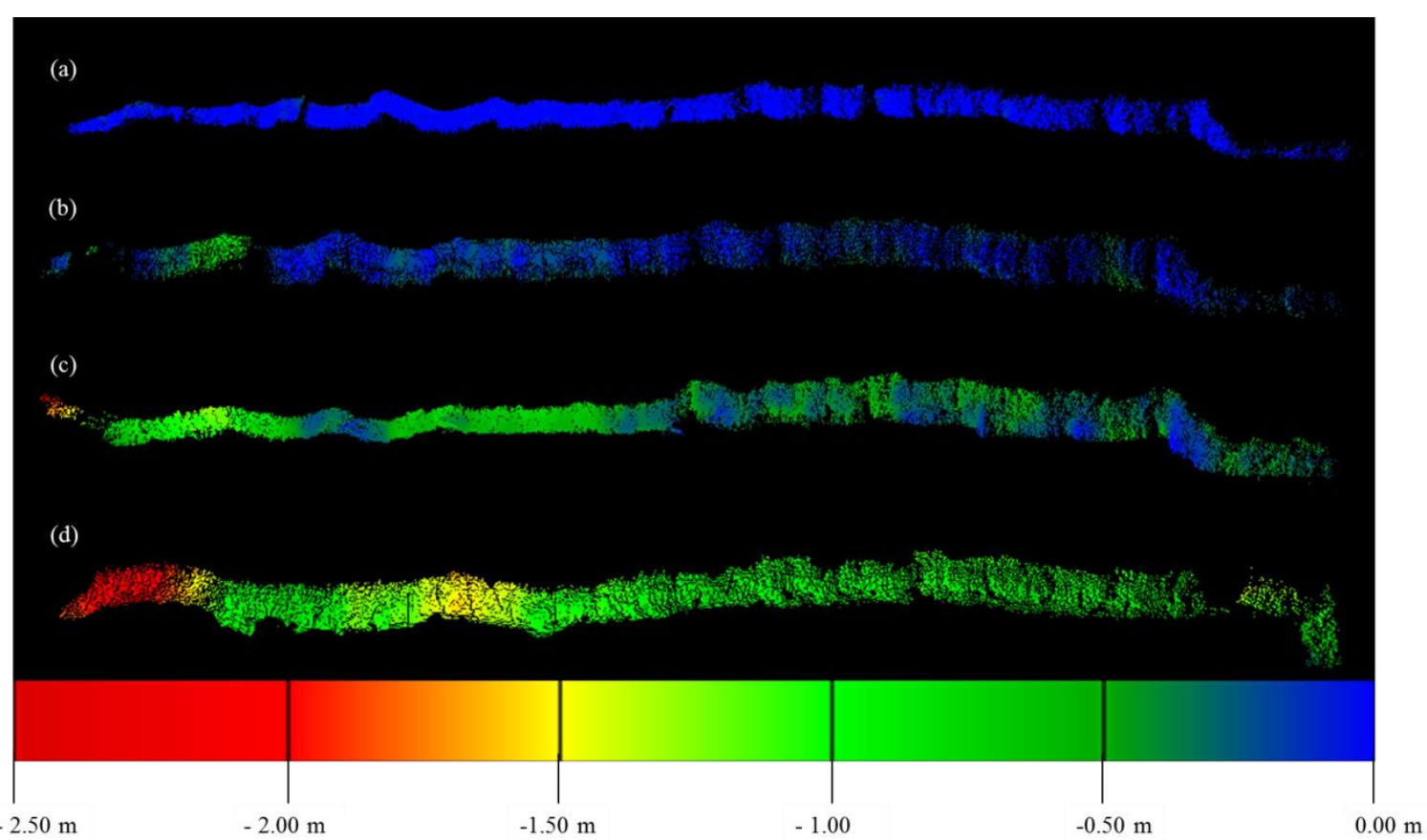

Figure 4. Cloud-to-Cloud (C2C) change analysis results for (a) interval 1, (b) interval 2, (c) interval 3, and (d) interval 4.

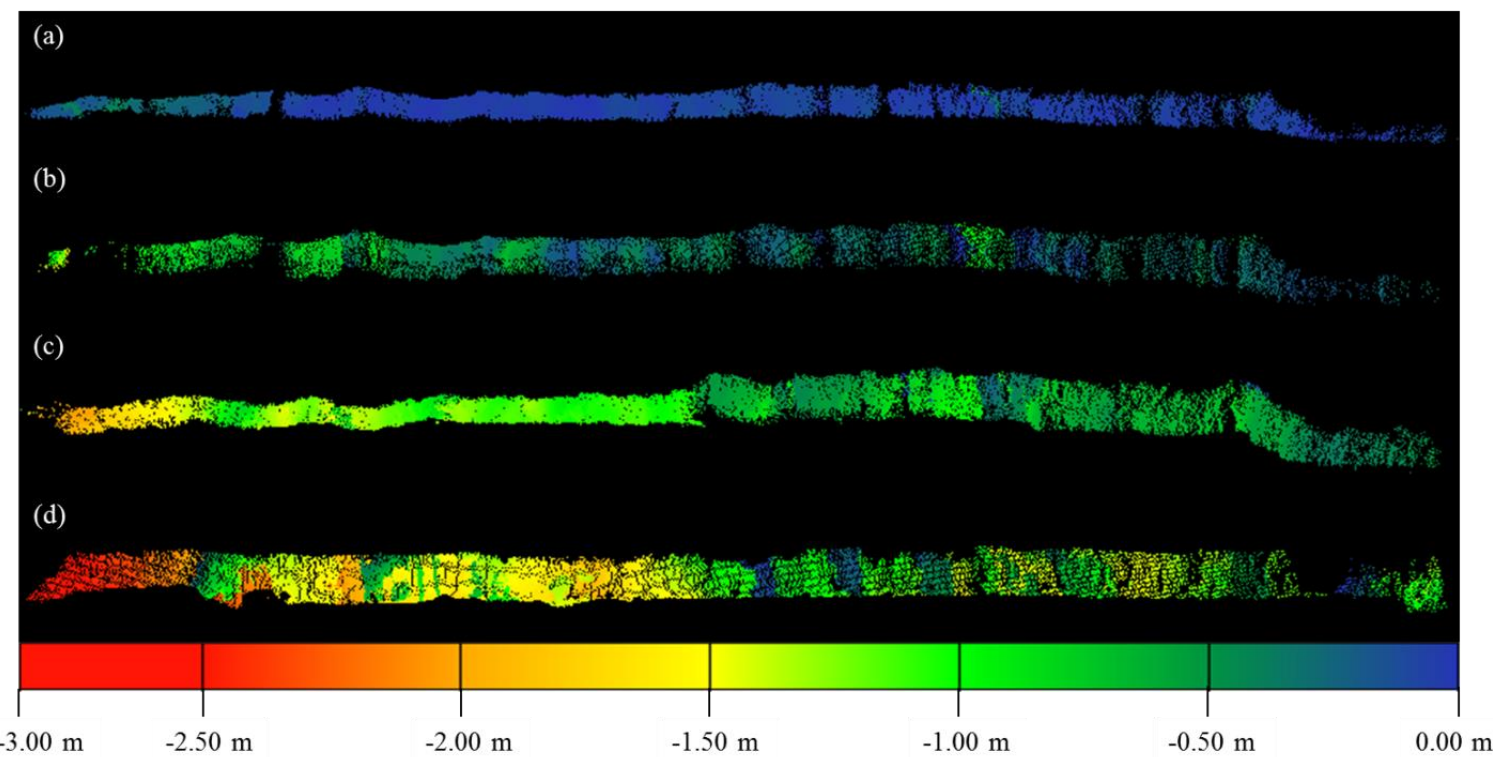

Figure 5. Multi-Model to Model Cloud Comparison (M3C2) change analysis results for (a) interval 1, (b) interval 2, (c) interval 3, and (d) interval 4. 
The root classification and voxelization analysis produced no clear relationship between root location and cumulative erosion, so we do not show the detailed results here. However, the method in general proved to be valid for combining lidar and traditional classification methods to produce a classified voxel that retained the appropriate spatial data along with attributes from the classification itself. The challenges of having very bright 'flare' sections of the image caused a reduction in the ability to classify the image as a whole. However, breaking up the image into different flare and non-flare areas improved the estimation along with using all RGB bands in the classification (Table 1).

Using the hindcast wind wave model that was constructed, the fit was strong between $\mathrm{C} 2 \mathrm{C}$ erosion metric during a given interval with the cumulative significant wave height during that same interval $\left(r^{2}=0.95\right)$ and the M3C2 metric was still more strongly correlated at $r^{2}=0.99$. While the relationships were strong, we note that the sample size for each consisted of four data points, as limited by the number of TLS sample intervals. Nevertheless, the fit was good. In addition, the cumulative significant wave height within each interval was strongly related with the number of days within each interval at $\mathrm{r}^{2}=0.99$.

\section{Discussion}

\section{Lessons Learned}

Lidar proved useful in quantifying $\mathrm{cm}$ scale erosion, and we found a strong relationship between erosion and wave energy. Lidar has been often used to measure changes occurring over an interval of time, but in this case we used it along with the voxel procedure and hindcast model to ask questions about the driving factors related to marsh edge retreat.

Using this methodology, we determined that lateral marsh retreat is linearly related to cumulative wave height. The management implication is that areas protected by an offshore breakwater or living shoreline could still experience considerable erosion if a large number of small waves are able to form behind the structure. Further research will need to be done to determine if this linear trend holds with other vertical terrestrial-to-water interfaces with different soil types. We are conducting further research to explore if a more universal relationship can be acquired from this study.

The strong relationship between wind speed, direction, and cumulative wave height supported the notion that waves arriving from the northwest during cold fronts are particularly responsible for erosion at our study site. The regression conducted herein did not specify the size or form of the incoming waves and the resulting erosion from individual waves, but rather showed that accumulating both large and small waves over time explained approximately $99 \%\left(r^{2}=0.99\right)$ of the observed erosion. Using the logic that cumulative wave height was linearly related to erosion, we are currently investigating whether individual waves contribute to erosion in a manner proportional to their size and breaking form in a separate study.

One interesting characteristic was that along the undulating shoreline (as can be seen in Figure 2), small protrusions of land approximately $0.5 \mathrm{~m}$ in length eroded faster than adjacent small embayments. Due to this pattern of erosion over time, one would expect that the shoreline would become linear rather than undulating. More research would be needed to develop a theory as to why this does not occur. However, one option is that the soil's resistivity to erosion is heterogeneously-distributed. Upon initial wave attack, some areas with weak soil cohesion erode quickly and become embayments. The bathymetry changes and the embayments are then more protected from direct wave attack. Conversely, the protrusions are then subjected to increased wave energy, and erode quickly, as recorded by our TLS at the time that we did the research. This phenomenon does certainly happen at larger spatial scales as well, where the left side of our general study area was slightly less exposed and the right side was more of a peninsula.

Another possible explanation is that the $0.5 \mathrm{~m}$ size of the undulations accords with the size at which chunks typically break off. In our visual observations, the edge usually failed in larger blocks of approximately this size. The scale of this failure could be due to roots holding the soil together in 
chunks of this size. We feel it is more likely that $0.5 \mathrm{~m}$ is the approximate scale at which slumping, caused by the weight of the soil along the vertical edge, exerts itself laterally back into the marsh platform, causing a seam to form and a chunk to break off. This process would then cause an undulating and irregular pattern.

Another possible explanation is that the scale of the undulations could match a cross-shore distribution of oscillatory wave energy, driven by infragravity motion. Indeed velocities measurements that we have conducted for related work show that there appears to be an infragravity beat that is moving cross-shore.

While no clear relationship could be gleaned from the comparison of root concentration and erosion, the method did provide the framework for further exploration and development of the analysis method that we used. Classifying voxels using $\mathrm{R}$ was effective computationally but many of the $\mathrm{R}$ software packages providing voxelization capabilities proved to be too cumbersome or hindered the scope of our application. Predominantly lidar packages in $\mathrm{R}$ and other languages are developed for aerial lidar and are mainly focused on forestry applications. Many of these packages make assumptions about point cloud orientation, assuming them to be more or less vertical (i.e., with the lidar collection obtained from an airplane or satellite as the platform). However, when measuring edges with a TLS, the point cloud is oriented differently, often 90 degrees off from the expectations of these packages. The point clouds can be transposed so that the vertical scarp face becomes the horizontal surface, but proper geospatial referencing is lost. These packages often provided impressive data visualization capabilities such as the VoxR packages, but they were either built for general application and produced only limited statistical output, or they were built for a specific application and our dataset was not transferable to their framework [29]. These limitations and the uniqueness of our dataset required us to develop a script that classified and assigned the point cloud data to voxels. Importantly, we were only interested using voxels as a way to group and compare data over time at different scales.

Difficulties also emerged when classifying the imagery data derived from the photographs taken by the TLS. For each point in the point cloud, the Leica ScanStation 2 provided the intensity and imagery data that was then used to classify the points. The classification procedure was similar to a traditional land cover classification but there were several limitations introduced by the hardware. The ScanStation 2 used a fixed exposure during acquisition which works when inside buildings or scanning at mid-day. However, for early morning or late afternoon scans, glare becomes an issue due to the angle of the sun. The times when we conducted the scans were dictated by the tidal range (an extreme low tide was required) rather than the potential for glare. Due to these tides occurring often in the early morning during this study, the photos were often overexposed when the scanner was pointed towards the rising sun and underexposed when pointed away. This fact led to large variance of imagery band values within a single class. To counteract the image "flares", we extracted smaller frames from the scan image and classified them separately, but this did not fully resolve the problem. Because we took a conservative classification approach, many points were excluded.

As an additional problem, the $\sim 2 \mathrm{~cm}$ point density was too coarse to consistently detect roots. It would have been possible to scan at a higher resolution in the field as the lidar mounting method proved to be quite robust and any fears of waves or wind shifting the scanner proved to be unfounded. However, for consistency sake, a $2 \mathrm{~cm}$ point density was used for the duration of the study. Because of the conservative classification approach mentioned above due to glare, the combination of these two problems led to a lower quantity of usable data. Since the current study, we have begun a $1 \mathrm{~mm}$ point density for similar research. We should also point out that as a marsh soil material erodes, the roots often remain and "spring" outward from the vertical edge face. When quantifying lateral erosion, if the point data associated with these roots are not removed then some portions of the edge may be erroneously reported as accretion rather than erosion. In the current study, we filtered all roots out before quantifying the erosion. However, in Lo et al. (2017) filtering does not appear to have been conducted, and based on tests with our own data, this can cause large errors [8]. 
Both the $\mathrm{M} 3 \mathrm{C} 2$ and $\mathrm{C} 2 \mathrm{C}$ metrics worked quite well and produced similar results, with $\mathrm{M} 3 \mathrm{C} 2$ producing the higher estimate for erosion. In most studies since this one, we have used $\mathrm{C} 2 \mathrm{C}$ metric to gather initial distances as it has been easier to use. However, the $\mathrm{M} 3 \mathrm{C} 2$ metric allows for a more refined assessment of the distances between the two clouds. Still with the M3C2, we have also had more issues making sure that it is properly parameterized, as small mistakes can cause large errors. Thus, for our research on edge erosion, the $\mathrm{C} 2 \mathrm{C}$ metric is more frequently used.

Finally, the manner in which we set up the TLS survey in the field worked quite well and future studies may find it useful to follow the procedures used. It is often difficult to identify the best location to set up a large and expensive piece of equipment, particularly when it is in an aquatic environment where water immersion could result in damage. This setup ensured that the TLS was always in the same position and safely perched above the water.

\section{Conclusions}

We found a strong correlation between wave energy and TLS-measured erosion. While a relationship between root concentration and subsequent erosion was not apparent, the methods used to implement the analysis were effective. For the future measurement of marsh edge erosion using TLS, we recommend:

1. Conducting measurements at the lowest possible tide;

2. Conducting measurements at mid-day or indoors if the scanner photography will be used for imagery classification of roots;

3. Developing custom packages to group point data within voxels for further analysis;

4. Scanning at $1 \mathrm{~mm}$ point density or finer to better detect fine roots;

5. Filtering out roots from point clouds to avoid miscalculating erosion/accretion;

6. Utilizing a custom tripod mount, and USGS benchmark methods, for safely mounting the TLS in the aqueous and soft-sediment of the salt marsh environment.

Author Contributions: Conceptualization, R.A.F. and A.D.J.; software, T.P.H.; validation, A.D.J. and T.P.H.; original draft preparation, R.A.F. and A.D.J.; final draft, T.P.H and R.A.F.; supervision, R.A.F.; funding Acquisition, R.A.F.

Funding: Funding for Arturo Delgado was provided, in part, by NASA's Carbon Cycle and Ecosystems Program (NNX14AM37G), the Hazelwood Act-State of Texas, and by the GI Bill-US Department of Veterans' Affairs

Acknowledgments: We would like to thank Ryan Sheridan and the Texas A\&M University Department of Ecosystem Science and Management LASERS lab for their technical support regarding the Leica ScanStation 2.

Conflicts of Interest: The authors declare no conflict of interest. The funding entities had no input in study design, data analysis methodology, or interpretation of final results.

\section{References}

1. Li, X.; Nicoletta, L.; Andrew, J.P. Wave-Driven Sediment Resuspension and Salt Marsh Frontal Erosion Alter the Export of Sediments from Macro-Tidal Estuaries. AMST 2019, 325, 17-28. [CrossRef]

2. Fagherazzi, S.; Wiberg, P.L. Importance of wind conditions, fetch, and water levels on wave-generated shear stresses in shallow intertidal basins. J. Geophys. Res. Earth Surf. 2009, 114, F03022. [CrossRef]

3. Leonardi, N.; Ganju, N.K.; Fagherazzi, S. A linear relationship between wave power and erosion determines salt-marsh resilience to violent storms and hurricanes. Proc. Natl. Acad. Sci. USA 2016, 113, 64-68. [CrossRef] [PubMed]

4. Marani, M.; D’Alpaos, A.D.; Lanzoni, S.; Santalucia, M. Understanding and predicting wave erosion of marsh edges. Geophys. Res. Lett. 2011, 38. [CrossRef]

5. Schwimmer, R. Rates and processes of marsh shoreline erosion in Rehoboth Bay, Delaware, U.S.A. J. Coast. Res. 2001, 17, 672-683.

6. Coops, H.; Geilen, N.; Verhij, H.J.; Boeters, R.; van der Velde, G. Interactions between waves, bank erosion and emergent vegetation: An experimental study in a wave tank. Aquat. Bot. 1996, 53, 187-198. [CrossRef] 
7. Feagin, R.A.; Lozada-Bernard, S.M.; Ravens, T.; Möller, I.; Yeager, K.M.; Baird, A.H. Does vegetation prevent wave erosion of salt marsh edges? Proc. Natl. Acad. Sci. USA 2009, 106, 10109-10113. [CrossRef] [PubMed]

8. Lo, V.; Bouma, T.; Van Belzen, J.; Van Colen, C.; Airoldi, L. Interactive effects of vegetation and sediment properties on erosion of salt marshes in the Northern Adriatic Sea. Mar. Environ. Res. 2017, 131, 32-42. [CrossRef] [PubMed]

9. Temmerman, S.; Bouma, T.J.; van de Koppel, J.; van der Wal, D.; de Vries, M.B.; Herman, P.M.J. Vegetation causes channel erosion in a tidal landscape. J. Geol. 2007, 35, 631-634. [CrossRef]

10. Gabet, E.J. Lateral migration and bank erosion in a saltmarsh tidal channel in San Francisco Bay, California. Estuaries 1998, 21, 745-753. [CrossRef]

11. Collins, B.D.; Sitar, N. Processes of coastal bluff erosion in weakly lithified soils, Pacifica, California, USA. J. Geol. 2008, 97, 483-501.

12. Farris, A.S.; Defne, Z.; Ganju, N.K. Identifying Slat Marsh Shorelines from Remotely Sensed Elevation Data and Imagery. Remote Sens. 2019, 11, 1795. [CrossRef]

13. Turner, R.E.; McClenachan, G.; Tweel, A.W. Island in the oil: Quantifying salt marsh shoreline erosion after the deepwater horizon oiling. Mar. Pollut. Bull. 2016, 1, 316-323. [CrossRef] [PubMed]

14. Young, A.P.; Olson, M.; Driscoll, N.; Flick, R.E.; Gutierrez, R.; Guza, R.T.; Johnstone, E.; Kuester, F. Comparison of Airborne and Terrestrial Lidar and Estimates of Seacliff Erosion in Southern California. Photogramm. Remote Sens. 2010, 76, 421-427. [CrossRef]

15. Guarnieri, A.; Vettore, A.; Pirotti, F.; Menenti, M.; Marani, M. Retrieval of small-relief marsh morphology from terrestrial laser scanner, optimal spatial filtering, and laser return intensity. J. Geol. 2009, 113, 12-20. [CrossRef]

16. Hoffmeister, D.; Tilly, N.; Curdt, C.; Aasen, H.; Ntageretzis, K.; Hadler, H.; Willershauser, T.; Vott, A.; Bareth, G. Terrestrial laser scanning for coastal geomorphologic research in Western Greece. ISPRS J. Photogramm. Remote Sens. 2012, 39, 511-516. [CrossRef]

17. Silva dos Santos, A.L.; Amaro, V.E.; Santos, M.S.T. Terrestrial laser scanner applied to monitoring beach morphological changes in a high energy coastal zone in Northeast Brazil. In Proceedings of the 7th International Terrestrial Laser Scanner User Meeting, Rome, Italy, 12-13 June 2014.

18. Feagin, R.A.; Williams, A.M.; Popescu, S.; Stukey, J.; Washington-Allen, R.A. The use of terrestrial laser scanning (TLS) in dune ecosystems: The lessons learned. J. Coast. Res. 2014, 30, 111-119. [CrossRef]

19. Schubert, J.E.; Gallien, T.W.; Majd, M.S.; Sanders, B.F. Terrestrial laser scanning of anthropogenic beach berm erosion and overtopping. J. Coast. Res. 2015, 31, 47-60. [CrossRef]

20. Nguyen, C.; Starek, M.; Tissot, P.; Gibeaut, J. Multi-scale voxel segmentation for terrestrial lidar data within marshes. In Proceedings of the American Geophysical Union Fall Meeting, San Francisco, CA, USA, 12-16 December 2016.

21. Nguyen, C.; Starek, M.; Tissot, P.; Gibeaut, J. Unsupervised Clustering Method of Complex Reduction of Terrestrial Lidar Data in Marshes. Remote Sens. 2018, 10, 133. [CrossRef]

22. Cahoon, D.R.; Hensel, P.; Rybczyk, J.; McKee, K.L.; Proffitt, C.E.; Perez, B.C. Mass tree mortality leads to mangrove peat collapse at Bay Islands, Honduras after Hurricane Mitch. J. Ecol. 2003, 91, 1093-1105. [CrossRef]

23. Cloud Compare. Available online: http://www.cloudcompare.org/ (accessed on 19 September 2015).

24. Lague, D.; Brodu, N.; Leroux, J. Accurate 3D comparison of complex topography with terrestrial laser scanner: Application to the Rangitikei canyon (N-Z). ISPRS J. Photogramm. Remote Sens. 2013, 82, 10-26. [CrossRef]

25. Barnhart, T.; Crosby, B. Comparing two methods of surface change detection on an evolving thermokarst using high-temporal-frequency terrestrial laser scanning, Selawik River, Alaska. Remote Sens. 2013, 5, 2813-2837. [CrossRef]

26. R Core Team, R: A Language and Environment for Statistical Computing, Vienna, Austria. Available online: https://www.R-project.org/ (accessed on 19 September-2015).

27. Mori, N.; Suzuki, T.; Kakuno, S. Noise of acoustic Doppler velocimeter data in bubbly flows. J. Eng. Mech. 2007, 133, 122-125. [CrossRef] 
28. Karimpour, A. OCEANLYZ, Ocean Wave Analyzing Toolbox, user manual. Available online: http://www. arashkarimpour.com/oceanlyz.html (accessed on 19 September 2015).

29. Lecinge, B.; Delagrange, S.; Messier, C. CloudCompare, version 2.6.1 14; VoxR: Metrics Extraction of Trees: Hannover Germany, 2018.

(C) 2019 by the authors. Licensee MDPI, Basel, Switzerland. This article is an open access article distributed under the terms and conditions of the Creative Commons Attribution (CC BY) license (http://creativecommons.org/licenses/by/4.0/). 